\title{
Human Umbilical Cord-Derived Mesenchymal Stem Cells Improve Learning and Memory Function in Hypoxic-Ischemic Brain-Damaged Rats via an IL-8-Mediated Secretion Mechanism Rather than Differentiation Pattern Induction
}

\author{
Xiaoqin Zhou ${ }^{a, b}$ Jialu Gua,b Yan Gu ${ }^{a, b}$ Mulan He $e^{a, b}$ Yang Bic Jie Chen ${ }^{a, b}$ \\ Tingyu Lia,b \\ ${ }^{a}$ Children's Nutrition Research Centre, Children's Hospital of Chongqing Medical University, Ministry \\ of Education Key Laboratory of Child Development and Disorders, Key Laboratory of Pediatrics in \\ Chongqing, ' Chongqing Engineering Research Centre of Stem Cell Therapy, 'Stem Cell Biology and \\ Therapy Laboratory, Children's Hospital of Chongqing Medical University, Chongqing, China
}

\section{Key Words}

Human umbilical cord-derived mesenchymal stem cells - Hypoxic-ischemic brain damage $\bullet$ IL-8 $\bullet$ Learning-memory function $\cdot$ Differentiation

\begin{abstract}
Background: MSCs are a promising therapeutic resource. Paracrine effects and the induction of differentiation patterns are thought to represent the two primary mechanisms underlying the therapeutic effects of mesenchymal stem cell (MSC) transplantation in vivo. However, it is unclear which mechanism is involved in the therapeutic effects of human umbilical cordderived MSC (hUC-MSC) transplantation. Methods and Results: Based on flow cytometry analysis, hUC-MSCs exhibited the morphological characteristics and surface markers of MSCs. Following directed neural induction, these cells displayed a neuron-like morphology and expressed high levels of neural markers. All types of hUC-MSCs, including differentiated and redifferentiated cells, promoted learning and memory function recovery in hypoxic-ischemic brain damaged (HIBD) rats. The hUC-MSCs secreted IL-8, which enhanced angiogenesis in the hippocampus via the JNK pathway. However, the differentiated and redifferentiated cells did not exert significantly greater therapeutic effects than the undifferentiated hUCMSCs. Conclusion: hUC-MSCs display the biological properties and neural differentiation potential of MSCs and provide therapeutic advantages by secreting IL-8, which participates in angiogenesis in the rat HIBD model. These data suggest that hUC-MSC transplantation improves the recovery of neuronal function via an IL-8-mediated secretion mechanism, whereas differentiation pattern induction was limited.
\end{abstract}

Copyright ( 2015 S. Karger AG, Basel

Jie Chen, PhD

and Tingyu Li, MD

KARGER 125
Children's Nutrition Research Center, Children's Hospital of Chongqing Medical University, No. 136, Zhongshan Er Road, Yuzhong District, Chongqing 400014 (China) Tel.+8623 63630913, Fax+862363622754

E-Mail jchen010@cqmu.edu.cn, E-Mail tyli@vip.sina.com 


\section{Cellular Physiology Cell Physiol Biochem 2015;35:2383-2401 \begin{tabular}{l|l} 
and Bioch 10.1159/000374040 & $\begin{array}{l}\text { C 2015 S. Karger AG, Basel } \\
\text { www.karger.com/cpb }\end{array}$ \\
\hline
\end{tabular}}

\section{Introduction}

Along with improvements in medical technology and therapeutic ability, the morbidity of hypoxic-ischemic brain damage (HIBD) has increased each year [1], demonstrating the need for improved treatment methods. Studies by other groups [2-4] and our research group $[5,6]$ have consistently demonstrated that mesenchymal stem cells (MSCs) transplanted from bone marrow represent a useful therapeutic strategy for treating neurological disorders. However, in many studies, the sources of MSCs have been limited to animals, with a long path to human clinical applications. Human umbilical cords are an attractive source of MSCs, as they display many advantages compared to other stem cell types, such as embryonic stem cells, in terms of reduced tumourigenicity, immunogenicity, and ethical issues. They also exhibit increased proliferation compared to bone marrow derived-MSCs and are considered more valuable for transplantation in stem cell therapy and research studies [7, 8]. However, to the best of our knowledge, it is unclear whether hUC-MSCs exhibit better biological characteristics and a higher potential for neural differentiation than other MSCs.

According to the accumulated evidence, the two primary mechanisms considered to underlie the therapeutic effects of MSCs in neurological disorders include the facilitation of the paracrine secretion of cytokines and the induction of neural differentiation patterns. Some studies have demonstrated that MSCs directly release or promote the release of various cytokines, including chemokines and growth and trophic factors, from the injured tissues [9]. These factors have been shown to ameliorate the inflammatory response [10], and promote neurogenesis and angiogenesis in the injured microenvironment $[11,12]$, and improve neurological function in the brains of injured animals. However, some studies have supported a different perspective regarding the potency of MSCs to induce neuronal differentiation. It has been proposed that implanted MSCs can differentiate into mature neurons and play a role in cell replacement. Nevertheless, fewer than 20\% of MSCs undergo neural differentiation in vivo $[13,14]$. Therefore, some research groups have attempted to improve this differentiation rate and thus increase the therapeutic potential of MSCs in various animal models by inducing these cells in vitro [15-17]. Some studies have suggested that hUC-MSCs improve neurological disease by either enhancing a paracrine effect or inducing differentiation patterns $[18,19]$. However, to the best of our knowledge, very few reports have addressed which mechanism participates in the therapeutic effects of these cells during HIBD.

In the current study, we first measured the biological characteristics and the neural differentiation and redifferentiation (neural differentiation for the second time) potential of hUC-MSCs in vitro. We then transplanted undifferentiated, differentiated and redifferentiated hUC-MSCs into HIBD rats to identify any therapeutic advantages in vivo. Finally, we investigated a possible mechanism by which hUC-MSC-secreted IL-8 might help promote the recovery of learning and spatial memory capabilities in HIBD rats.

\section{Materials and Methods}

Culture and expansion of hUC-MSCS

hUC-MSCs were supplied by the Chongqing stem cell bank. All protocols involving human subjects were approved by the Ethics Committee of the Children's Hospital of Chongqing Medical University (Approval number: 024/2013). The cells were cultured in Dulbecco's modified Eagle's medium/ F12 (DMEM/F12; 1:1; Gibco, Carlsbad, CA, USA) supplemented with 10\% FBS (Gibco), 100 units $/ \mathrm{ml}$ penicillin, and $100 \mu \mathrm{g} / \mathrm{ml}$ streptomycin at $37^{\circ} \mathrm{C}$ in a humidified incubator containing $5 \% \mathrm{CO}_{2}$. When the cells reached $90 \%$ confluence, they were digested using trypsin/EDTA (Gibco) and reseeded in new culture dishes. Unless indicated otherwise, all hUC-MSCs used in the subsequent experiments were from passage 5 to passage 10.

Cytogenetic analysis

For the cytogenetic analysis, hUC-MSCs with $50 \%$ confluence in $75-\mathrm{cm}^{2}$ flasks (Corning Costar Corp, NY, USA) at various passages (P2, P10, and P15) were incubated at $37^{\circ} \mathrm{C}$ in colcemid (Irvine Scientific, 


\section{Cellular Physiology Cell Physiol Biochem 2015;35:2383-2401 \begin{tabular}{ll|l} 
and Biochemistry & $\begin{array}{l}\text { DOI: 10.1159/000374040 } \\
\text { Published online: April 16, } 2015\end{array}$ & $\begin{array}{l}\text { ○ 2015 S. Karger AG, Basel } \\
\text { www.karger.com/cpb }\end{array}$ \\
\hline
\end{tabular} Zhou et al.: IL-8 from hUC-MSCs Improves HIBD Injury}

CA, USA) at a final concentration of $1 \mu \mathrm{g} / \mathrm{ml}$ for $3.5 \mathrm{~h}$ to induce cell cycle arrest at metaphase. The cells in metaphase were karyotyped in accordance with the recommendations of the International System for Human Cytogenetic Nomenclature (ISCN 2009).

\section{Flow cytometry}

To stain the hUC-MSCs, cultured cells at passage 2 were trypsinised using trypsin/EDTA, washed with PBS and resuspended at a concentration of $10^{6}$ cells $/ \mathrm{ml}$. The cell suspensions were incubated with different antibodies (1:100 dilution) for $30 \mathrm{~min}$ at RT in the dark and analysed using a FACSCanto II system (BD Biosciences). The CD34-PE, CD29-PE, CD45-FITC, HLA-ABC PE and HLA-DR-FITC primary antibodies were purchased from eBioscience (San Diego, CA, USA). The CD44-FITC, CD90-PE and CD105-PE primary antibodies were purchased from BD Biosciences (San Jose, CA, USA), and the recommended isotype control for PE and FITC were purchased from 4A Biotech Co., Ltd. (Beijing, China).

\section{Induction of neuronal differentiation and redifferentiation}

All chemicals used for the modified neuronal medium (MNM) were purchased from Sigma (St. Louis, MO, USA). Neuronal differentiation and redifferentiation were induced according to a previously described method [20]. Briefly, hUC-MSCs at passage 5 were seeded at $4 \times 10^{5} /$ well in a 6 -well culture plate (Corning Costar Corp). Cells were pre-induced in all-trans-retinoic acid (ATRA) ( $1 \mu \mathrm{mol} / \mathrm{L})$ for 24 hours, and the undifferentiated hUC-MSCs were induced using MNM for 24 hours to achieve neuronal differentiation status (Dif). The MNM was replaced with complete culture medium (DMEM/F12 containing 10\% FBS) for 24 hours following neuronal differentiation. Cells were then transferred to MNM for another 24 hours to achieve neuronal redifferentiation status (Re-Dif). Cells presenting neuron-like morphology were identified as positive when calculating differentiation efficiency, and the neural induction rate was measured using Image J software. Three independent experiments were performed and evaluated.

\section{RNA extraction and analysis}

In brief, total RNA was extracted using an RNA Extraction Kit (Bioteke Co., Ltd, Beijing, China). RNA was reverse-transcribed using a PrimeScript RT reagent Kit according to the manufacturer's protocol. Realtime PCR reactions were performed using a RealMasterMix kit (SYBR Green; Takara Biomedicals, Osaka, Japan) and a Bio-Rad Real-Time PCR system. All samples were normalised to the expression level of $\beta$-actin. The primer sequences are listed in Table 1.

\section{Western blot}

Total protein was extracted using RIPA buffer containing PMSF (Bioteke Co. Ltd). SDS-PAGE gels of different concentrations (Beyotime, Shanghai, China) were prepared, and proteins of interest were electrophoretically separated according to their molecular weight. The anti-NSE, anti-MAP2, anti- $\beta$ tubulin-III and anti-IL-8 primary antibodies were purchased from Abcam (Cambridge, MA, USA). The antip-JNK, anti-JNK, anti-PECAM-1 and anti- $\beta$-actin primary antibodies and the HRP-conjugated secondary antibodies were purchased from Santa Cruz Biotechnology (Santa Cruz, CA, USA). The proteins of interest were visualised using Luminata Crescendo Western HRP Substrate (Millipore, Billerica, MA, USA) and the Syngene G-Box Imaging System.

Table 1. Primer Sequences for the genes

\begin{tabular}{|c|c|c|c|}
\hline Gene name & $\begin{array}{l}\text { Accession } \\
\text { number }\end{array}$ & Sequence & PCR products \\
\hline Human NSE & NM_001975 & $\begin{array}{l}\text { S: 5'- TTGGATGGGACTGAGAACA-3' } \\
\text { A: 5'-GCACAGGCAGGATGAGGT-3' }\end{array}$ & $154 \mathrm{bp}$ \\
\hline Human MAP2 & HSU01828 & $\begin{array}{l}\text { S: 5'- ACCTCAACACCCACTACCC - 3' } \\
\text { A: 5'- CTCACTCGGCACCAAGAT - } 3^{\prime}\end{array}$ & $156 \mathrm{bp}$ \\
\hline Human $\beta$-tubulin-III & HSU47634 & $\begin{array}{l}\text { S: 5'-CAGCAAGGTGCGTGAGGA -3' } \\
\text { A: 5'-GCGTGGCGTTGTAGGGTT -3' }\end{array}$ & $104 \mathrm{bp}$ \\
\hline Human IL-8 & NM_000584.3 & $\begin{array}{l}\text { S: 5'-ATAAAGACATACTCCAAACCT -3' } \\
\text { A: 5'-AACTTCTCCACAACCCTC - } 3^{\prime}\end{array}$ & $167 \mathrm{bp}$ \\
\hline Human $\beta$-actin & X00351.1 & $\begin{array}{l}\text { S: 5'-GTGAAGGTGACAGCAGTCGGTT -3' } \\
\text { A: 5'-GAGAAGTGGGGTGGCTTTTAGGA -3' }\end{array}$ & $159 \mathrm{bp}$ \\
\hline
\end{tabular}




\section{Cellular Physiology Cell Physiol Biochem 2015;35:2383-2401 \begin{tabular}{ll|l} 
DOI: 10.1159/000374040 & $\begin{array}{l}\text { C } 2015 \mathrm{~S} \text {. Karger AG, Basel } \\
\text { www.karger.com/cpb }\end{array}$ \\
\hline
\end{tabular} \\ Zhou et al.: IL-8 from hUC-MSCs Improves HIBD Injury}

Enzyme-linked immunosorbent assay (ELISA)

IL-8, TIMP-1, CCL2, CXCL1 and VEGF production were examined using commercially available ELISA kits. The IL-8, CXCL1 and VEGF commercial ELISA kits were purchased from Raybiotech (Norcross, GA, USA), and the TIMP-1 and CCL2 commercial ELISA kits were purchased from 4A Biotech Co., Ltd. The experimental procedure was performed in accordance with the corresponding reagent kit protocol. The optical density at $450 \mathrm{~nm}$ was recorded using a microtiter plate reader (Thermo).

\section{Establishment of silL-8-hUC-MSC cell line}

The silL-8 lentivirus was targeted to human chemokine ligand 8 (CXCL8, NM-000584.3) and was constructed by Neuron Biotech (Shanghai, China). hUC-MSCs at a confluence of 50-60\% in a 6-well plate were infected with the silL-8 lentivirus at a multiplicity of infection (MOI) of 2.5. After $48 \mathrm{~h}$, green fluorescent protein (GFP) was detected under a microscope, and $0.5 \mu \mathrm{g} / \mathrm{ml}$ puromycin was added to select for silL8-infected hUC-MSCs. A single silL-8-infected hUC-MSC was seeded into a 96-well plate to obtain stable cell lines for further experiments. The silL-8-hUC-MSC stable cell line carried a sequence specific for hIL-8 (gccaaggagtgctaaagaact) for hIL-8.

\section{Microarray analysis}

Total RNA was extracted from different experimental groups using TRIzol reagent (Invitrogen, Carlsbad, CA). After purification and quality assessment, the bio-tagged cRNAs were fragmented into strands of 35-200 bases in length according to the manufacturer's protocol. Then, the cRNAs were hybridised to the Human Genome U133 Plus 2.0 array, which contains approximately 54675 probes, for $16 \mathrm{~h}$ at $45^{\circ} \mathrm{C}$. All samples were prepared in triplicate. The hybridisation data were analysed using Affymetrix ${ }^{\circledR}$ GeneChip $\AA$ Command Console ${ }^{\circledR}$ Software. The expression profiles were examined via hierarchical cluster analysis using Cluster version 2.11 software. Affymetrix ${ }^{\circledR}$ NetAff ${ }^{\mathrm{TM}}$ Analysis Center software was used for gene ontology analysis. The data were considered to be significantly different when the expression was altered by at least two-fold, and the differentially expressed genes were selected for further analyses. The microarray data was submitted to Gene Expression Omnibus (GEO), and the submission number is GSE65631.

\section{Animal studies}

All animal experiments were approved by the Ethical Committee of Chongqing Medical University. Sprague Dawley (SD) rats were purchased from the Experimental Animal Center of Chongqing Medical University [Certificate: SCXK (Yu) 2012-0001]. All rats were housed in a specific pathogen-free (SPF) laboratory. The animal housing rooms were maintained at a constant temperature $\left(25^{\circ} \mathrm{C}\right)$ in a $12 \mathrm{~h} / 12 \mathrm{~h}$ light-dark cycle, and the animals were provided with access to food and water ad libitum.

\section{Rat HIBD model and cell transplantation}

The HIBD model was established according to the Rice model [21]. After 5 days, $2 \times 10^{5}$ cells suspended in $5 \mu \mathrm{L}$ of sterile PBS were transplanted into the HIBD rats $(n=76,12$ days old $)$ via intracerebroventricular injection. The injection site was located $1.2 \mathrm{~mm}$ posterior to the bregma, $1.4 \mathrm{~mm}$ to the left of the lambdoid suture and at a needle depth of $3.6 \mathrm{~mm}$. The injection rate was $1 \mu \mathrm{L} / \mathrm{min}$, and a microinjection instrument was used to control the injection, which lasted a total of $5 \mathrm{~min}$. The needle remained in the lateral ventricle for 2 min. The HIBD control group ( $n=27$ ) was injected with the same volume of sterile PBS. The sham group $(n=18)$ received the sham surgery without hypoxia-ischemia or cell transplantation.

\section{Histopathology and immunofluorescence}

The pups were sacrificed two days after cell transplantation, and the brain tissues from the sham $\operatorname{group}(n=6)$, HIBD group(n=6), hUC-MSC group(n=6), GFP-hUC-MSC group(n=3) and siIL-8-hUC-MSC $\operatorname{group}(n=3)$ were collected. For haematoxylin-eosin (HE) staining, 4- $\mu$ m continuous coronary slices on glass slides were stained with HE, and the pathology and morphology of the cells were analysed using a light microscope (Nikon). For double-immunofluorescence labelling, 30\% sucrose paraformaldehyde was applied to dehydrate the tissue sections. These sections were immunostained with monoclonal mouse anti-BrdU (1:500 dilution, Sigma) and rabbit anti-PECAM-1(1:100 dilution) antibodies at $4^{\circ} \mathrm{C}$ for $20 \mathrm{~h}$. The primary antibodies were visualised using Alexa Fluor 488 chicken anti-mouse IgG and Cy3-conjugated Affinipure Goat Anti-rabbit IgG. The fluorescent antibodies against BrdU and PECAM-1 were purchased from 


\section{Cellular Physiology Cell Physiol Biochem 2015;35:2383-2401 \begin{tabular}{ll|l} 
DOI: 10.1159/000374040 & $\begin{array}{l}\text { C } 2015 \mathrm{~S} \text {. Karger AG, Basel } \\
\text { www.karger.com/cpb }\end{array}$ \\
\hline
\end{tabular}}

Invitrogen or Proteintech (Wuhan, China). Images were captured via laser scanning confocal microscopy (Nikon).

\section{Morris water maze test}

The Morris water maze test was performed as previously described $[5,6]$. Briefly, four weeks after cell transplantation, the rats from the sham group ( $n=9,6$ weeks old), HIBD group ( $n=18)$, hUC-MSC group $(n=17)$, Dif group $(n=12)$, Re-Dif group $(n=10)$, GFP-hUC-MSC group $(n=8)$ and silL-8-hUC-MSC group $(n=8)$ were subjected to the Morris water maze test. The procedure lasted a total of six days. The first day consisted of the visual platform test. Each experimental rat underwent four trials of $60 \mathrm{~s}$ in four quadrants, and the time (escape latency) and distance (path length) required to locate the platform were recorded. During the next four days of training, the average time to locate the platform on the four trials was recorded. On the final day, the probe trial was performed by removing the platform, and the number of times that the rats crossed the former platform location in $60 \mathrm{~s}$ was recorded.

\section{Object-in-place task}

This behavioural test was performed in a $1 \mathrm{~m}^{2}$ open-topped box constructed of black Plexiglas. During the pretraining phase, the animals ( $n=42,6$ weeks old) were placed in the empty box to adapt to the environment for $10 \mathrm{~min}$ for two consecutive days. During the sample phase (day 3), four different shaped toys were placed at the four corners of the box, and the animals were allowed to explore the novel objects for $5 \mathrm{~min}$. During the delay period ( $5 \mathrm{~min}$ ), all objects were cleaned with alcohol to remove olfactory cues and any sawdust, and two adjacent toys were exchanged (excluding the two diagonal toys). During the test phase ( $3 \mathrm{~min}$ ), the animals were placed in the box again, and the time spent exploring the four toys was recorded. In the subsequent analysis, the ratio of the time spent exploring the two novel objects (changed position) to the time spent exploring the two familiar objects (unchanged position) was compared.

\section{In vivo electrophysiology}

All chemicals used for the electrophysiology experiments were purchased from Sigma. The rats $(\mathrm{n}=17,8$ weeks old) were anesthetised via intraperitoneal injection of pentobarbitone $(60 \mathrm{mg} / \mathrm{kg})$. The hippocampal slices were transferred to a chamber placed on the stage of an upright microscope (Nikon E600FN, Tokyo, Japan) and perfused with oxygen-saturated artificial cerebrospinal fluid (ACSF) at $35^{\circ} \mathrm{C}$. The recording and stimulating electrodes were placed in the CA1 area of the hippocampal slice. Extracellular field excitatory postsynaptic potentials (fEPSPs) were evoked using a single test stimulus, and the test stimulus current was adjusted to half of the maximal amplitude to establish a steady baseline ( $\geq 20 \mathrm{~min}$ ) before tetanic stimulation. To induce LTP, high frequency stimulation (HFS) was applied, and the effects were recorded every $2 \mathrm{~min}$ for $60 \mathrm{~min}$.

\section{Statistical analysis}

The results are presented as the means \pm S.E.M. One-way analysis of variance (ANOVA) was used for multivariate data analysis, and Student's t test was used for statistical analysis. A value of $\mathrm{P} \leq 0.05$ was considered to be significant.

\section{Results}

\section{Identification of hUC-MSCS}

The hUC-MSCs cultured on a culture dish surface exhibited a spindle-shaped fibroblastlike morphology and were arranged in a spiral (Fig. 1A). The cells at passages 10 and 15 demonstrated no apparent morphological differences compared to the cells at passage 2 (Fig. 1A middle and right). To determine the karyotypic stability of increasing cell passages, trypsin and Wright's stain-banding analysis were performed on hUC-MSCs at passages 2, 10 and 15. As shown in Fig. 1B, chromosomal aberration of the hUC-MSCs was not observed during 15 generations, suggesting that these hUC-MSCs maintained a normal chromosomal structure for at least 15 passages. Subsequently, cell-surface antigen expression was further examined via flow cytometry. The data displayed in Fig. 1C show that the hUC-MSCs 


\section{Cellular Physiology Cell Physiol Biochem 2015;35:2383-2401

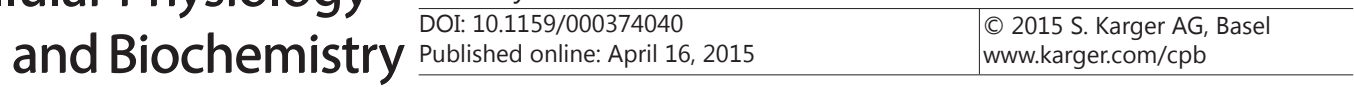

A
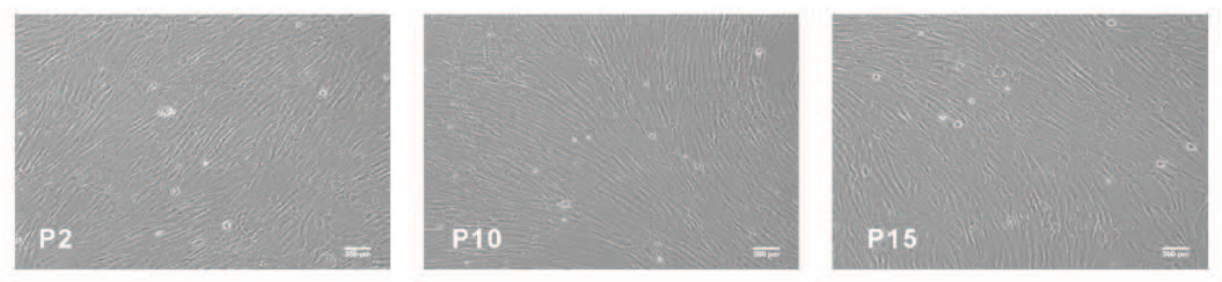

B
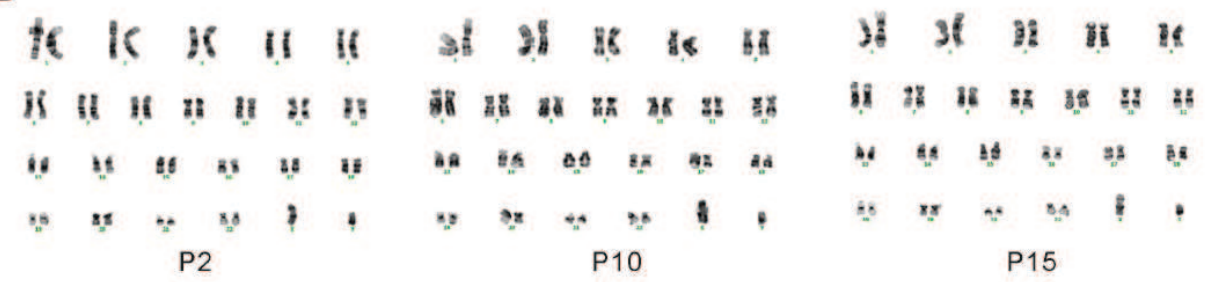

C
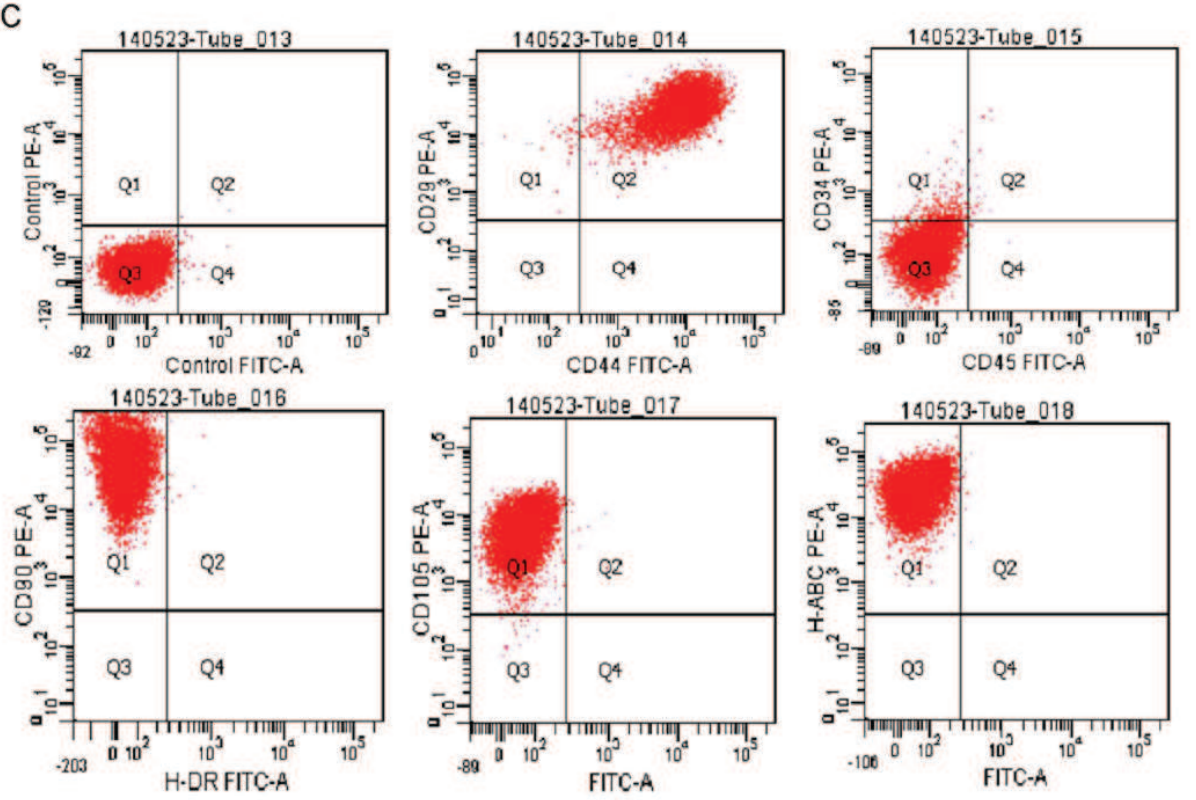

Fig. 1. Preliminary identification of hUC-MSCs. (A), Morphology of hUC-MSCs at passages 2, 10 and 15 (Scale bar=300 $\mu \mathrm{m}$ ). (B), Detection of the chromosomal karyotype in the different passages of hUC-MSCs (passages 2, 10 and 15). (C), Flow cytometry analysis of surface marker expression in hUC-MSCs.

positively expressed CD29, CD44, CD90, CD105, and HLA-ABC but not CD34, CD45 or HLADR. Taken together, these findings suggest that the hUC-MSCs in the present study exhibit the morphological characteristics of MSCs and express MSC-related surface markers, which verified their suitability as transplantation cells for subsequent experiments.

Neuronal differentiation and redifferentiation potency of hUC-MSCs in vitro

To investigate whether the hUC-MSCs displayed neuronal differentiation and redifferentiation potency, we subjected hUC-MSCs to a differentiation- and redifferentiationinducing protocol. As shown in Fig. 2A (middle panel), following neuronal differentiation (Dif group), the cells exhibited morphology similar to hUC-MSCs. However, the cells subjected to neuronal redifferentiation (Re-Dif group) displayed a dramatically neuron-like morphology, with a round, bright cell body and neurite-like extensions. The neural induction rate was nearly $80 \%$ (Fig. 2A right).

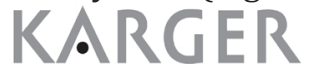




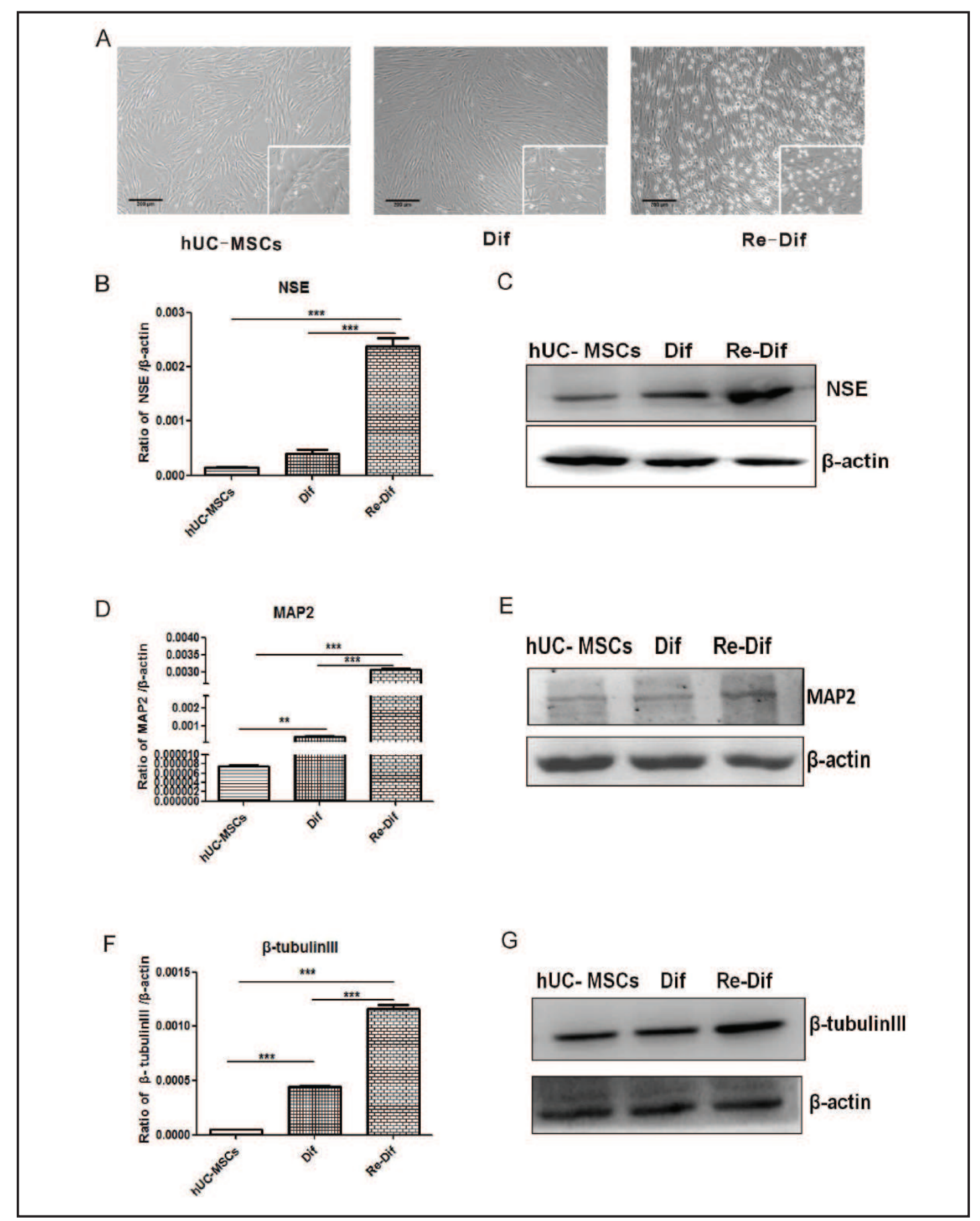

Fig. 2. Induction of the neuronal differentiation and redifferentiation potency of hUC-MSCs. (A), Changes in morphology following neuronal MNM-induced differentiation and redifferentiation of hUC-MSCs (Scale bar $=200 \mu \mathrm{m}$ ). (B-C), The mRNA and protein expression levels of NSE in undifferentiated, differentiated and redifferentiated hUC-MSCs. (D-E), The levels of MAP2 mRNA and protein expression in undifferentiated, differentiated and redifferentiated hUC-MSCs. (F-G), The levels of $\beta$-tubulin-III mRNA and protein expression in undifferentiated, differentiated and redifferentiated hUC-MSCs. All results were normalised to $\beta$-actin expression, and the data shown were obtained from triplicate experiments. The relative mRNA expression level was calculated as the expression level of the target gene relative to that of $\beta$-actin via $\mathrm{qPCR}\left({ }^{* *} \mathrm{p}<0.01\right.$; $\left.{ }^{* * *} \mathrm{p}<0.001\right)$; the protein expression level was evaluated via Western blot, and representative images are shown.

\section{KARGER}




\section{Cellular Physiology Cell Physiol Biochem 2015;35:2383-2401 \\ \begin{tabular}{ll|l} 
and Biochemistry $10.1159 / 000374040$ & $\begin{array}{l}\text { DO 2015 S. Karger AG, Basel } \\
\text { Published online: April 16, } 2015\end{array}$ & \begin{tabular}{l} 
( 2015 ww.karger.com/cpb \\
\cline { 2 - 3 } Zhou et al: IL-8 from hUC-MSCs Improves HIBD Injury
\end{tabular}
\end{tabular}}

Next, the expression levels of neural-specific markers, including NSE, MAP2 and $\beta$-tubulin-III, were examined in the three induced groups. Fig. 2B, 2D and $2 \mathrm{~F}$ reveal that the mRNA expression levels of NSE, MAP2 and $\beta$-tubulin-III were gradually increased following the induction of differentiation and redifferentiation. In response to the redifferentiation treatment, we found that the levels of the three markers were sharply increased ${ }^{* *} \mathrm{P}<0.01$, ${ }^{* * *} \mathrm{P}<0.001$, one-way ANOVA). The changes in the protein expression levels of these three neural-specific markers were completely consistent with the changes in their mRNA expression (Fig. 2C, 2E, 2G), suggesting that the hUC-MSCs in the present study were successfully induced to differentiate into neuron-like cells expressing high levels of neural markers via an in vitro redifferentiation method.

\section{Therapeutic effect of hUC-MSC transplantation in the HIBD rat model}

To confirm the therapeutic efficacy of hUC-MSC transplantation, comparison experiments consisting of brain histopathological evaluation, rat behavioural tests and electrophysiological examination of brain slices were performed in vivo. Based on HE staining, the periventricular brain tissue displayed uneven, diffuse staining and nuclear condensation (Fig. 3A middle), and the cell morphology in the HIBD pups was altered compared to the sham rats. In contrast, hUC-MSC transplantation partially alleviated these changes (Fig. 3A right). To analyse the spatial learning and memory ability of the HIBD rats, the Morris water maze test was performed four weeks following hUC-MSC transplantation. On the visible platform tests (Day 1), no difference in the escape latency or the path length was detected ( $p>0.05$, one-way ANOVA), which indicated that the HIBD model and cell transplantation did not affect the movement or visual ability of the rats (Fig. 3B-3C). During the hidden platform training (Day 2-5), all of the groups demonstrated gradual decreases in the escape latency. The HIBD group exhibited a longer escape latency than the sham group $\left({ }^{*} \mathrm{P}<0.05,{ }^{* *} \mathrm{P}<0.01,{ }^{* * *} \mathrm{P}<0.001\right.$, Sham vs. HIBD, one-way ANOVA), whereas the escape latency was significantly reduced in the HIBD group transplanted with hUC-MSCs (\#P $<0.05$, HIBD vs. hUC-MSCs, one-way ANOVA) (Fig. 3D). On the probe trial tests (Day 6), the hUCMSC-treated group entered the platform quadrant significantly more than the HIBD group, although less than the sham group $\left({ }^{* * *} \mathrm{P}<0.001\right.$, Sham vs. HIBD; ${ }^{*} \mathrm{P}<0.05$, HIBD vs. hUCMSCs, Sham vs. hUC-MSCs) (Fig. 3E). We also examined the spatial configuration memory of the rats for objects using an object-in-place task. The data in Fig. 3F show that the HIBD rats spent less time investigating the two objects at the new location than the sham rats ( ${ }^{* * *} \mathrm{P}<0.001$, Sham vs. HIBD); however, the novel object exploration time was significantly increased following hUC-MSC treatment $\left({ }^{*} \mathrm{P}<0.05\right.$, HIBD vs. hUC-MSCs).

To examine whether hUC-MSC transplantation facilitates hippocampal synaptic plasticity, we recorded fEPSPs in the hippocampal CA1 region of brain slices. The basal level of fEPSPs during the $20 \mathrm{~min}$ pre-HFS and the $60 \mathrm{~min}$ post-HFS were recorded in the three groups. At 30 min post-HFS application, the incremental mean slope of the fEPSPs in response to HFS in the HIBD group $(110.1 \% \pm 11.7 \%$ of baseline, $n=5)$ was lower than that in both the hUC-MSC $(153.1 \% \pm 17.5 \%$ of baseline, $\mathrm{n}=6)$ and sham groups $(167 \% \pm 21.8 \%$ of baseline, $\mathrm{n}=6)\left({ }^{*} \mathrm{P}<0.05\right.$, HIBD vs. hUC-MSCs; ${ }^{* * *} \mathrm{P}<0.001$, HIBD vs. Sham) (Fig. 3G). The fEPSP level induced by HFS remained constant until the end of the experimental recording $(60 \mathrm{~min}$ ) in the three groups. The above results suggest that hUC-MSC transplantation improved spatial learning and memory function and enhanced hippocampal synaptic plasticity in HIBD rats.

Therapeutic potential of neuronal differentiation and redifferentiation of hUC-MSCs in vivo

To evaluate the effects of the differentiated and redifferentiated cells on biological function in vivo, we transplanted differentiated or redifferentiated hUC-MSCs into the HIBD rats. On the Morris water maze test, no significant difference in the escape latency or the path length during the Day 1 test was detected between the three groups $(\mathrm{P}>0.05$, one-way ANOVA) (Fig. 4A-4B). During the hidden platform acquisition training phase (from Day 2-5), the escape latency of all three groups gradually decreased, demonstrating that the rats in 


\section{\begin{tabular}{cl|l} 
Cellular Physiology & Cell Physiol Biochem 2015;35:2383-2401 \\
\cline { 2 - 3 } DOI: 10.1159/000374040 & $\begin{array}{l}\text { O 2015 S. Karger AG, Basel } \\
\text { www.karger.com/cpb }\end{array}$
\end{tabular}
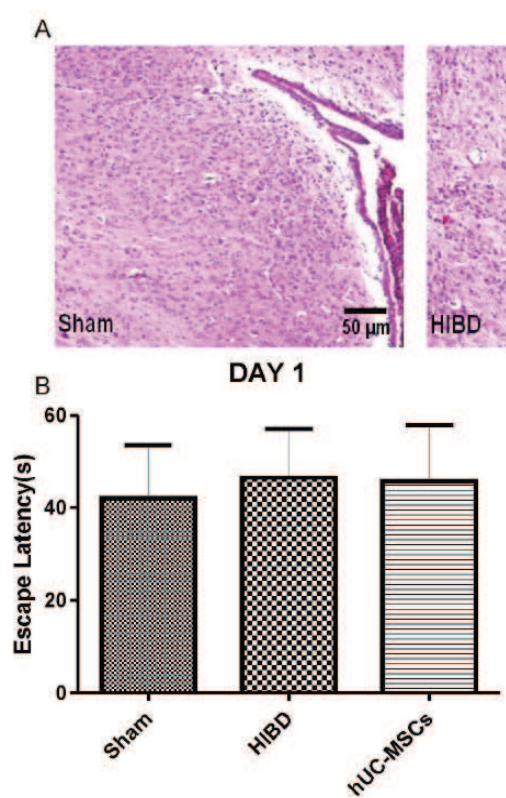

D

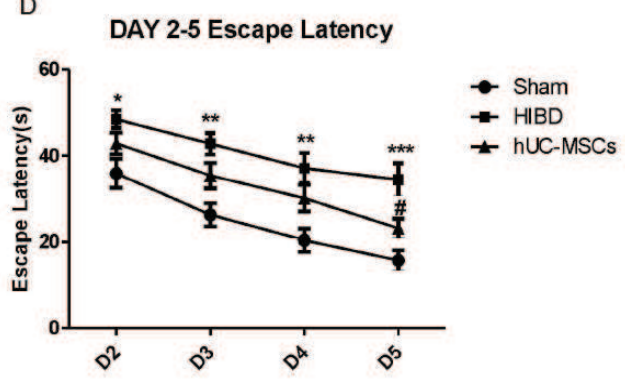

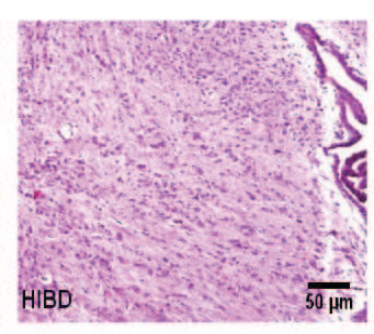

C DAY 1

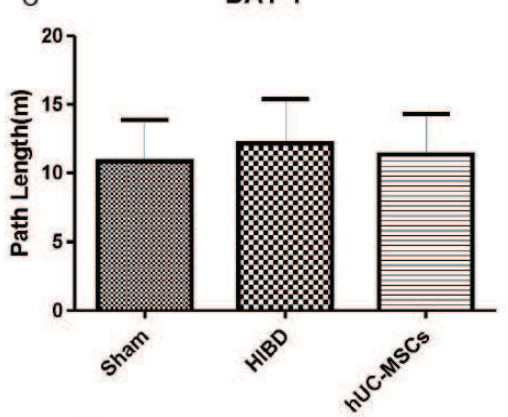

E

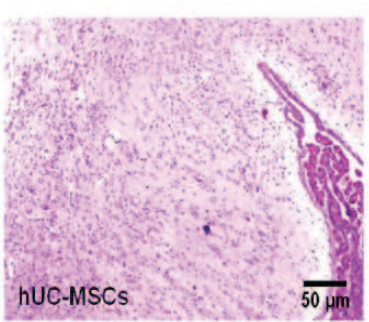

DAY 1
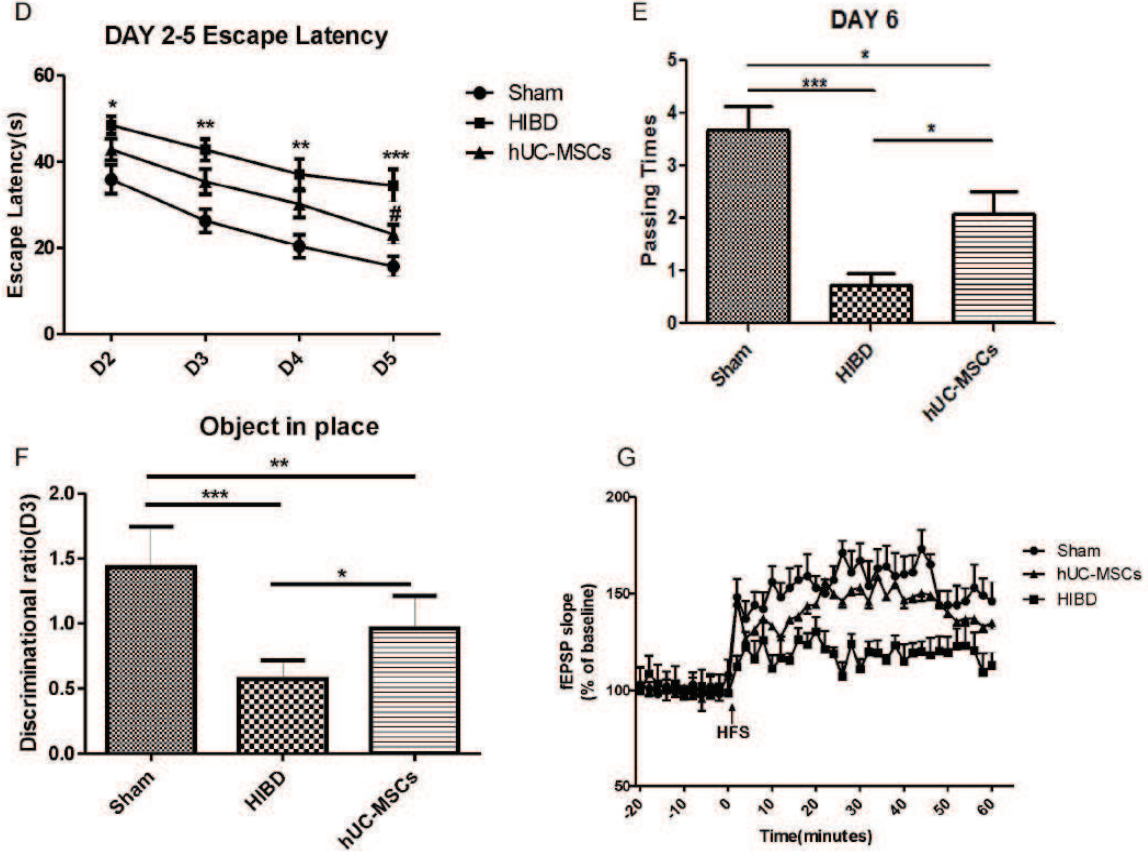

Fig. 3. Therapeutic effect of hUC-MSC transplantation into HIBD rats. (A), Histopathological changes in the brain tissue surrounding the lateral ventricle in the three groups (Sham, HIBD and hUC-MSCs) as demonstrated by HE staining (Scale bar=50 $\mu \mathrm{m})$. (B-C), The time and distance travelled by rats when locating the platform on the visual tests (Day 1) of the Morris water maze in the Sham ( $=9$ ), HIBD ( $=18$ ) and hUC-MSC groups (n=17). (D), The escape latency of the three groups on training days 2 to $5\left({ }^{*} \mathrm{p}<0.05,{ }^{* *} \mathrm{p}<0.01\right.$, ${ }^{* * *} \mathrm{p}<0.001$, Sham vs. HIBD; \#p<0.05, HIBD vs. hUC-MSCs). (E), The number of entries into the platform quadrant by the different treatment groups on day $6\left(^{* * *} \mathrm{p}<0.001\right.$, Sham vs. HIBD, ${ }^{*} \mathrm{p}<0.05$, HIBD vs. hUCMSCs, Sham vs. hUC-MSCs). (F), The discrimination ratio of the exploration time during the test phase of the object-in-place task in the three groups (Sham (n=9), HIBD (n=8) and hUC-MSCs (n=8)). (G), The standardised fEPSP slope in the Sham $(n=6)$, HIBD $(n=5)$ and hUC-MSC groups $(n=6)$.

each group showed spatial memory for the underwater platform, and no difference between the hUC-MSC, Dif and Re-Dif groups was detected ( $P>0.05$, one-way ANOVA) (Fig. 4C). 


\section{Cellular Physiology Cell Physiol Biochem 2015;35:2383-2401 \begin{tabular}{l|l} 
DOI: 10.1159/000374040 & o 2015 S. Karger AG, Basel
\end{tabular} and Biochemistry Published online: April 16, 2015 www.karger.com/cpb}

A

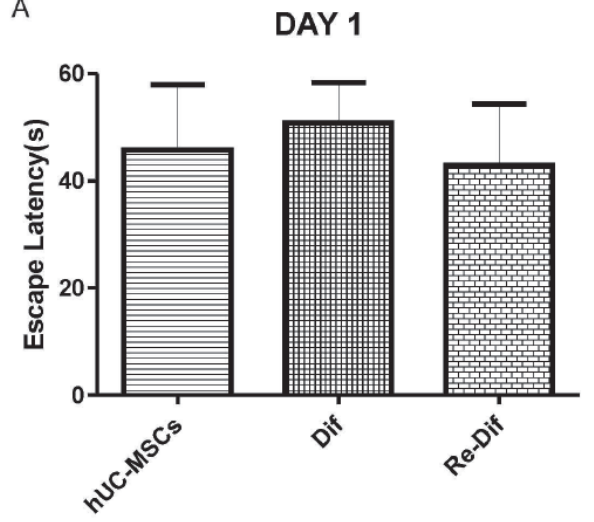

C

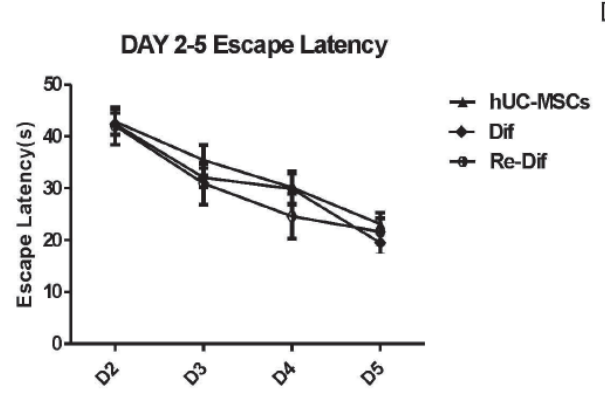

B
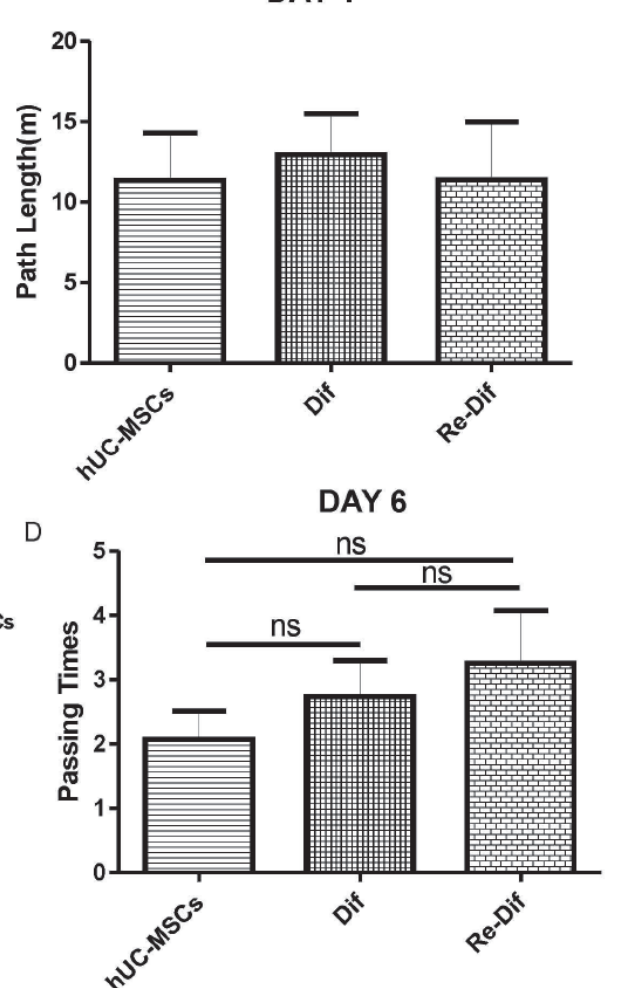

E

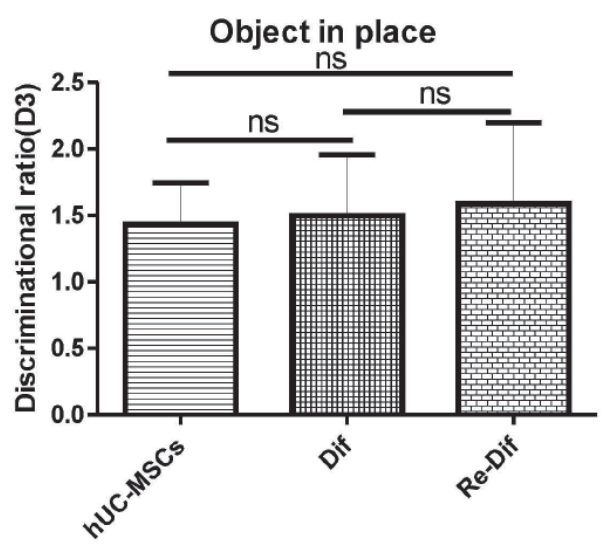

Fig. 4. Evaluation of the therapeutic effect of the differentiated and redifferentiated hUC-MSCs transplanted into HIBD rats. (A-B), Escape latency and path length of the undifferentiated $(n=17)$, Dif $(n=12)$ and Re-Dif $(\mathrm{n}=10)$ groups during visual training (Day 1 ) on the Morris water maze test. (C), Escape latency on the hidden platform tests (from Day 2-5) of the Morris water maze in the three groups ( $p>0.05)$. (D), Number of platform quadrant entries by the three groups during the probe trial (Day6) of the Morris water maze. No significant difference between the three groups $(\mathrm{p}>0.05)$ was detected. $(\mathrm{E})$, Discrimination between the novel and familiar objects in the undifferentiated $(n=8)$, Dif $(n=9)$ and Re-Dif groups $(n=8)(p>0.05)$.

During the probe trial (Day 6), although the number of platform quadrant entries displayed a slight increase in both the Dif and Re-Dif groups, no significant difference between the three groups was detected (P>0.05, one-way ANOVA) (Fig. 4D). On the object-in-place task, the three groups exhibited similar memory for the novel objects, and no significant differences 


\section{Cellular Physiology Cell Physiol Biochem 2015;35:2383-2401 \begin{tabular}{l|l|l}
\hline DOI: 10.1159/000374040 & O 2015 S. Karger AG, Basel
\end{tabular} and Biochemistry Published online: April 16, 2015 www.karger.com/cpb}

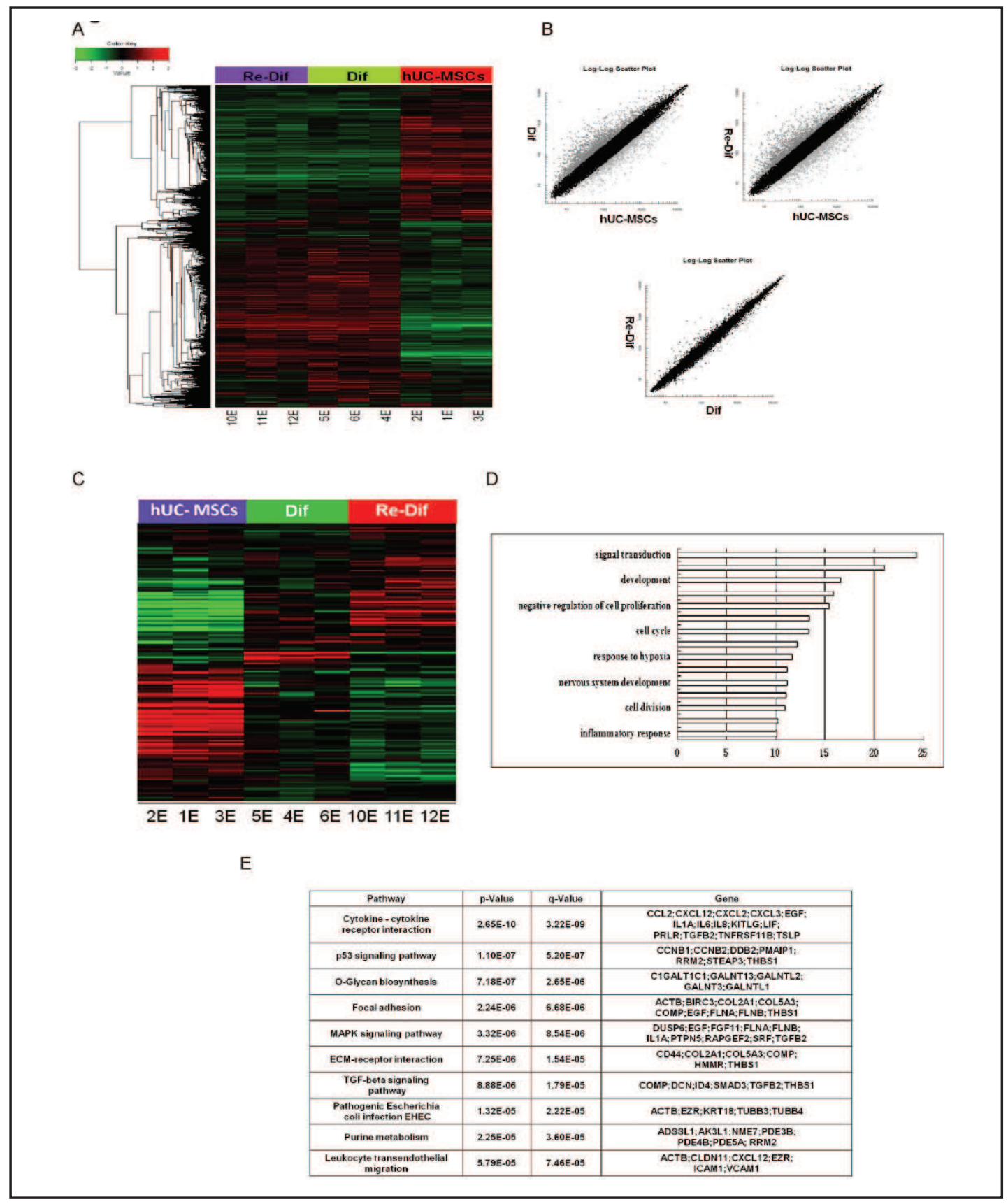

Fig. 5. The differences in gene expression between the undifferentiated, Dif and Re-Dif hUC-MSCs in vitro as determined by a gene expression profiling array. (A), Cluster analysis of the gene expression pattern in the undifferentiated, Dif and Re-Dif groups. The data shown were obtained from biological triplicates. (B), Comparative analysis of the gene scatter plot of the three groups. (C), Cluster analysis of 483 genes that were differentially expressed between the undifferentiated, Dif and Re-Dif groups. (D), Gene ontology analysis of the 483 differentially expressed genes. The predominant biological functions are illustrated in the histogram. (E), KEGG pathway analysis of the 483 differentially expressed genes. The top 10 pathways ranked by p-value are shown.

were observed (P>0.05, one-way ANOVA) (Fig. 4E). These results suggested that similar to undifferentiated hUC-MSCs, both differentiated and redifferentiated hUC-MSCs promote neural function recovery in HIBD rats; however, the Dif and Re-Dif cells did not confer greater 


\section{Cellular Physiology Cell Physiol Biochem 2015;35:2383-2401 \begin{tabular}{l|l} 
DOI: 10.1159/000374040 & O 2015 S. Karger AG, Basel
\end{tabular} and Biochemistry Published online: April 16, 2015 www.karger.com/cpb

Fig. 6. The hUC-MSCs secreted high levels of IL-8 both in vitro and in vivo. (A), The bar graph shows the levels of 36 cytokine genes expressed in hUC-MSCs based on the Affymetrix U133 GeneChip data. (B), The levels of different cytokines in the culture supernatants of hUC-MSCs. The data shown were obtained from triplicate experiments $\left({ }^{* * *} \mathrm{p}<0.001\right.$, IL-8 vs. TIMP-1). (C), The levels of hIL-8 secretion in rat brain tissue in the Sham, HIBD and hUC-MSC groups $\quad\left({ }^{*} \mathrm{p}<0.05\right.$, HIBD vs. hUC-MSCs, Sham vs. hUC-MSCs). (D), The IL-8 protein expression level in rat brain tissue from the three groups.

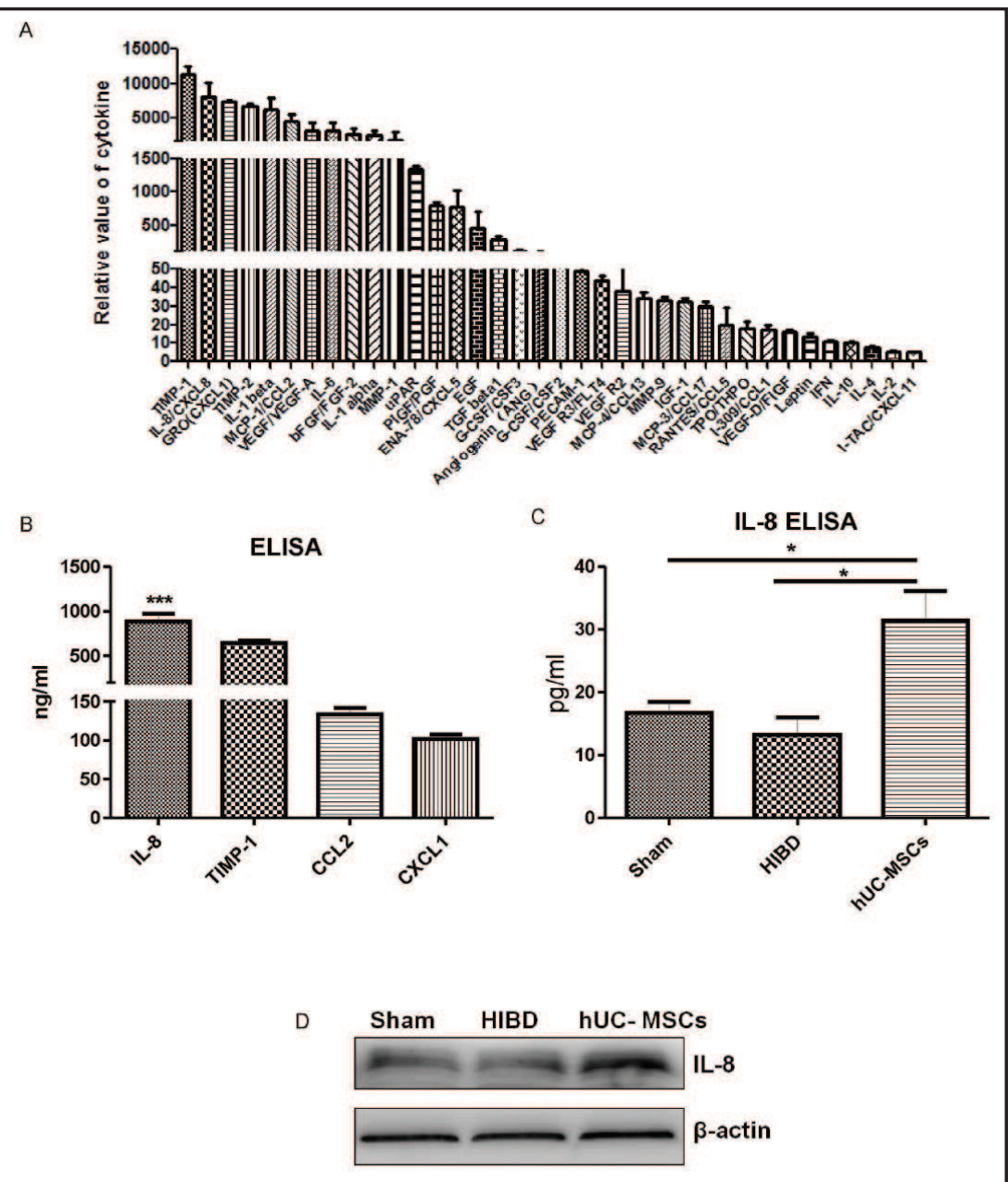

therapeutic advantages than the undifferentiated hUC-MSCs, even though they expressed higher levels of neuronal markers in vitro.

The differences in the gene expression profiles between the undifferentiated, Dif and Re-Dif hUC-MSCs in vitro

To explain the high in vitro neural potential and the lack of therapeutic advantages of Dif and Re-Dif hUC-MSCs in vivo, we employed a gene expression profiling microarray to determine the differences in gene expression between the undifferentiated, Dif and ReDif hUC-MSCs. According to genome cluster analysis and the scatter plot, the Dif and ReDif groups displayed similar gene expression patterns, which were very different from that of the undifferentiated hUC-MSCs (Fig. 5A-5B). Then, we screened the consistently altered genes in the three groups (consistently increased or decreased) and selected 483 genes that displayed significantly different expression according to the cluster analysis. As shown in Fig. 5C, following neural differentiation and redifferentiation, the Dif group exhibited little change, and the Re-Dif group showed the opposite gene expression pattern to the undifferentiated hUC-MSCs group. Furthermore, these differentially expressed genes were analysed via gene ontology and biological function analyses. The histogram in Fig. 5D shows the top 15 biological functions of the differentially expressed genes, which included signal transduction, development, negative regulation of cell proliferation, cell cycle, and nervous system development. KEGG-pathway analysis was applied to determine the possible pathways that participate in the neural differentiation and redifferentiation process. Of the many possible signalling pathways, the cytokine-cytokine receptor interaction pathway 


\section{Cellular Physiology Cell Physiol Biochem 2015;35:2383-2401 \begin{tabular}{l|l}
\hline DOI: 10.1159/000374040 & O 2015 S. Karger AG, Basel \\
\hline
\end{tabular}}

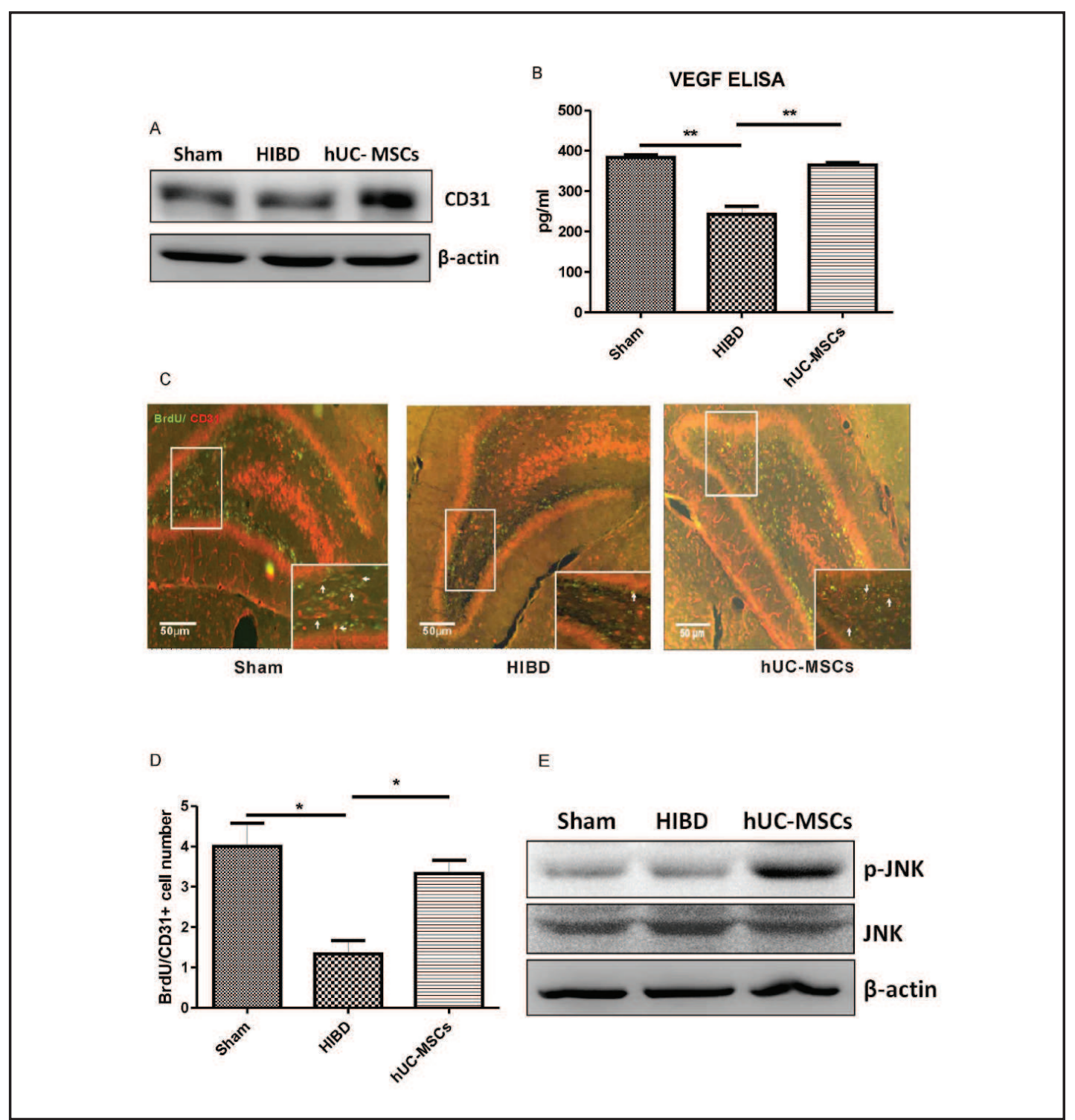

Fig. 7. hUC-MSC transplantation enhanced angiogenesis in the hippocampus of HIBD rats via the JNK pathway. (A), Western blots of the CD31 protein expression levels in brain tissue from the Sham, HIBD and hUC-MSC groups are shown. (B), The differences in the VEGF secretion level between the three groups were demonstrated by ELISA using triplicate preparations ( ${ }^{* *} \mathrm{p}<0.01$, Sham vs. HIBD, HIBD vs. hUC-MSCs). (C), The number of endothelial cells displaying CD31 and BrdU double-labelling in the three groups was determined via immunofluorescence (Scale bar=50 $\mu \mathrm{m}$ ). (D), Immunofluorescence analysis was performed to quantify the number of BrdU+/CD31+ cells in the rat hippocampus $\left({ }^{*} p<0.05\right.$, HIBD vs. hUC-MSCs, Sham vs. HIBD). (E), Western blot was performed to determine the protein expression levels of p-JNK and JNK in rat brain tissue from the Sham, HIBD and hUC-MSC groups.

displayed the most significant difference (Fig. 5E). The above data indicate that the induction of differentiation and redifferentiation in hUC-MSCs is a gradual process that results in distinct gene expression patterns and that the cytokine-cytokine receptor interaction pathway is primarily involved in this process.

The possible mechanism underlying the effects of hUC-MSC treatment

The data from the gene expression profiling chip assay suggested that cytokines from the hUC-MSCs play an important role in improving the recovery of learning and memory 

Cellular Physiology Cell Physiol Biochem 2015;35:2383-2401 \begin{tabular}{l|l} 
DOI: 10.1159/000374040 & O 2015 S. Karger AG, Basel
\end{tabular} and Biochemistry Published online: April 16, $2015 \quad$ www.karger.com/cpb

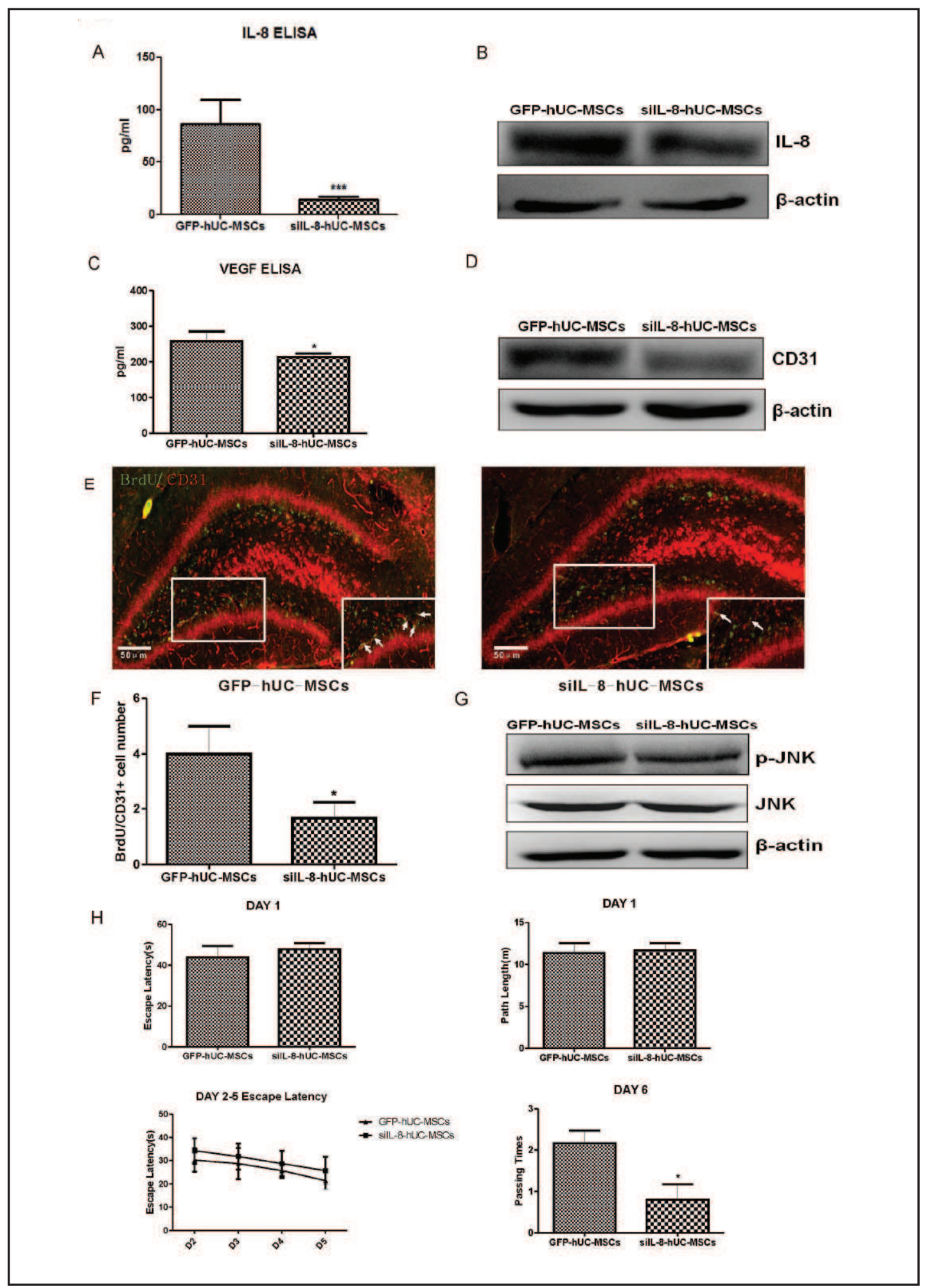

Fig. 8. silL-8-hUC-MSC transplantation suppressed angiogenesis in the hippocampus of HIBD rats via the JNK pathway. (A), Levels of hIL-8 secretion in rat brain tissue in the GFP-hUC-MSC and silL-8- hUC-MSC groups $\left({ }^{* * *} \mathrm{p}<0.001\right)$. (B), IL-8 protein expression in rat brain tissue from the two groups. (C), Levels of VEGF secretion in rat brain tissue in the two transplantation groups $\left({ }^{*} \mathrm{p}<0.05\right)$. (D), Western blots of CD31 protein expression levels in brain tissue from the GFP-hUC-MSC and siIL-8-hUC-MSC groups are shown. (E), The number of endothelial cells displaying BrdU and CD31 double-labelling in the two groups was 


\section{Cellular Physiology Cell Physiol Biochem 2015;35:2383-2401 \begin{tabular}{ll|l}
\hline DOI: 10.1159/000374040 & $\begin{array}{l}\text { C 2015 S. Karger AG, Basel } \\
\text { www.karger.com/cpb }\end{array}$ \\
\hline
\end{tabular}}

determined via immunofluorescence (Scale bar $=50 \mu \mathrm{m}$ ). Triplicate preparations were performed, and representative images are shown. (F), Quantitative analysis of the number of BrdU+/CD31+ cells in the rat hippocampus $\left({ }^{*} \mathrm{p}<0.05\right) .(\mathrm{G})$, Levels of $\mathrm{p}-\mathrm{JNK}$ and JNK protein expression in rat brain tissue from the GFPhUC-MSC and silL-8- hUC-MSC groups. $(\mathrm{H})$, Morris water maze test results in the GFP-hUC-MSC group $(\mathrm{n}=8)$ and siIL-8-hUC-MSC group $(\mathrm{n}=8)\left({ }^{*} \mathrm{p}<0.05\right)$.

function in HIBD rats following hUC-MSC transplantation. Therefore, to explore the molecular mechanism underlying the therapeutic effect of hUC-MSCs, the expression levels of various cytokines were analysed according to the gene expression profiling chip assay data. We found that the hUC-MSCs expressed high levels of many cytokine genes, such as TIMP-1, IL-8, and CXCL1 (Fig. 6A). Furthermore, ELISA was applied to verify the gene chip results. As shown in Fig. 6B, IL-8 was the cytokine that showed the highest level of secretion by hUC-MSCs (***P $<0.001$, IL-8 vs. TIMP-1, one-way ANOVA). In addition, we detected a change in the IL-8 protein level in rat brain tissue and, surprisingly, found that both the levels of hIL-8 secretion and IL-8 protein expression were significantly increased in the hUCMSC-transplanted brain tissue $(* \mathrm{P}<0.05$, HIBD vs. hUC-MSCs, Sham vs. hUC-MSCs, one-way ANOVA) (Fig. 6C-6D), suggesting that IL-8 secretion by hUC-MSCs may participate in the restoration of learning and memory function in the HIBD rats.

IL-8 is an important factor that promotes angiogenesis and participates in many physiological processes. Angiogenesis was evaluated to elucidate the role of IL-8 in vivo. As shown in Fig. 7A-7B, the levels of CD31 protein expression and VEGF secretion in the hUC-MSC group were significantly higher than those in the HIBD group ${ }^{* *} \mathrm{P}<0.01, \quad \mathrm{HIBD}$ vs. hUC-MSCs; ${ }^{* *} \mathrm{P}<0.01$, Sham vs. HIBD). Moreover, the immunofluorescence results revealed that the number of endothelial cells displaying CD31 and BrdU double-labelling was significantly increased in the hUC-MSC group compared to the HIBD group $\left({ }^{*} \mathrm{P}<0.05\right.$, HIBD vs. hUC-MSCs, Sham vs. HIBD, one-way ANOVA) (Fig. 7C-7D). Moreover, the level of p-JNK protein expression was clearly increased in the HIBD brain tissue following hUC-MSC transplantation compared to the sham and HIBD brain tissue, even though no significant difference in the level of total JNK protein expression was detected between the three groups (Fig. 7E). These data indicate that IL-8 secreted by hUC-MSCs may regulates angiogenesis in the hippocampus of HIBD rats via the JNK signalling pathway.

silL-8-hUC-MSC transplantation inhibits angiogenesis in the hippocampus of HIBD rats via the JNK pathway

To verify the hypothesis that IL-8 secreted by hUC-MSCs regulates angiogenesis in the hippocampus of HIBD rats via the JNK signalling pathway, we generated stable cell lines of silL-8-hUC-MSCs and GFP-hUC-MSCs and transplanted them into the HIBD rats. For two days following transplantation, the levels of hIL-8 secretion and IL-8 protein expression in rat brain tissue were statistically significantly lower in the silL-8-hUC-MSC group than in the GFP-hUC-MSC group ${ }^{* * *} p<0.001$, Student's t test) (Fig. 8A-8B). During subsequent followup, the levels of VEGF secretion and CD31 protein expression were significantly reduced in the silL-8-hUC-MSC group compared to the GFP-hUC-MSC group $\left({ }^{*} \mathrm{P}<0.05\right.$, Student's $t$ test) (Fig. 8C-8D). Immunofluorescence results revealed that the number of endothelial cells displaying CD31 and BrdU double-labelling was significantly decreased in the silL-8-hUCMSC group $\left({ }^{*} \mathrm{P}<0.05\right.$, Student's t test) (Fig. 8E-8F). In addition, the levels of $\mathrm{p}$-JNK protein expression clearly decreased following silL-8-hUC-MSC transplantation, although total JNK protein expression was not significantly different (Fig. 8G). On the Morris water maze test, the silL-8-hUC-MSC group exhibited a longer escape latency (Fig. 8H lower left), although these rats spent less time in the platform quadrant than the GFP-hUC-MSC group $\left({ }^{*} \mathrm{P}<0.05\right.$, Student's t test) (Fig. 8H lower right). The above results further support our hypothesis that IL-8 secreted by hUC-MSCs regulates angiogenesis in the hippocampus of HIBD rats via the JNK signalling pathway. 


\section{Cellular Physiology Cell Physiol Biochem 2015;35:2383-2401 \\ \begin{tabular}{ll|l} 
and Biochemistry 10.1159/000374040 & Published online: April 16, 2015 & $\begin{array}{l}\text { C } 2015 \mathrm{~S} \text {. Karger AG, Basel } \\
\text { www.karger.com/cpb }\end{array}$ \\
\cline { 2 - 3 }
\end{tabular}}

\section{Discussion}

hUC-MSCs are a promising type of MSC with clinical applications. According to the ISCT standards, which include the criteria for defining human MSCs [22], the hUC-MSCs in the present study exhibited the morphological characteristics and immunophenotype of hMSCs, which was consistent with other studies [23, 24]. Furthermore, the hUC-MSCs exhibited excellent proliferative capacity and chromosomal stability until passage 15 , indicating that they are safe for clinical application. The multi-lineage differentiation potential of these was verified previously [25]; therefore, we did not repeat these experiments in the current study.

MSCs display the ability to cross the germinal layer to differentiate into neuron-like cells and produce greater functional results than undifferentiated stem cells, suggesting that MSCs represent excellent transplantation cells for cell-based therapy and tissue engineering $[26,27]$. Additionally, our previous studies have demonstrated that differentiated and redifferentiated BMSCs from rats exhibited neural phenotypes and biological functions [20, 28]. Whether hUC-MSCs, a special type of MSC, display neuronal differentiation potency was unclear. To address this issue, hUC-MSCs were subjected to a differentiation induction programme. Surprisingly, the differentiated cells did not exhibit a neuron-like morphology, although their neural marker levels were higher than those of the undifferentiated hUCMSCs. This interesting finding prompted us to conduct a redifferentiation induction protocol on the hUC-MSCs. Interestingly, the redifferentiated cells exhibited dramatic morphological changes and expressed much higher levels of neural markers than the differentiated hUCMSCs, suggesting that the hUC-MSCs used in the present study display in vitro neuronal differentiation potency. Moreover, because the differentiated hUC-MSCs maintained a similar morphology to the undifferentiated hUC-MSCs, hUC-MSCs from humans may display more strictly conservative properties than MSCs derived from rats. The initial differentiation was not sufficient to counteract the conservative properties and alter the cytoskeleton, although redifferentiation induced morphological changes and increased neural marker expression. Further studies should be conducted to elucidate the precise mechanism underlying these changes.

To evaluate the therapeutic effects of the three states of hUC-MSCs, differentiated, redifferentiated or undifferentiated hUC-MSCs were transplanted into HIBD rats. Because previous studies have reported that ischemia-related gene expression occurs in a timedependent manner at $72 \mathrm{~h}$ or later following ischemia [29], we defined an effective therapeutic window as consisting of no more than 10 days [30, 31]. Intracerebral transplantation may serve as the most appropriate method for treating nervous system diseases because this method results in the most extensive grafting of the implanted cells to the injured tissue. Four weeks after transplantation, neurobehavioral function was assessed. Our data revealed that the hUC-MSCs in all the three states promoted the recovery of neural function in HIBD rats, indicating that hUC-MSC transplantation showed an advantage in HIBD rats, which was consistent with a previous study [18]. However, the results also showed that the differentiated and redifferentiated cells were not able to produce more significant therapeutic advantages than the undifferentiated hUC-MSCs. Some studies have shown that inducing differentiation is not necessary; for example, undifferentiated adipose-derived stem cells (ASCs) were effective in promoting nerve regeneration [32], and the undifferentiated and differentiated cells improved function to a similar extent [33]. Our results verified that inducing differentiation and redifferentiation neural patterns may not be a necessary component of the treatment process.

To explain the high in vitro neural potential and the lack of therapeutic advantages of hUC-MSCs in vivo, a gene expression profiling microarray was used in the present study. Based on analysis of the chip results, the induction of differentiation and redifferentiation in hUC-MSCs was clearly a gradual process that produced distinct gene expression patterns. Importantly, the cytokine-cytokine receptor interaction pathway primarily participated in this process. 


\section{Cellular Physiology Cell Physiol Biochem 2015;35:2383-2401 \\ \begin{tabular}{ll|l} 
and Biochemistry $10.1159 / 000374040$ & $\begin{array}{l}\text { Do } 2015 \mathrm{~S} \text {. Karger AG, Basel } \\
\text { Published online: April 16, } 2015\end{array}$ & www.karger.com/cpb \\
\cline { 2 - 3 } Zhou et al: IL-8 from hUC-MSCs Improves HIBD Injury
\end{tabular}}

The regulation of the injury microenvironment by secreted cytokines and the induction of differentiation are the two primary mechanisms thought to contribute to the therapeutic effects of MSCs [34, 35]. As mentioned previously, the differentiated and redifferentiated cells did not further restore biological functions compared to undifferentiated hUC-MSCs in the current study, and the results of gene expression profiling suggested that cytokine production in hUC-MSCs merited further investigation. We found that IL-8 was the most abundantly secreted cytokine by hUC-MSCs in vitro. Surprisingly, the levels of both hIL8 secretion and IL-8 protein expression were significantly increased in the hUC-MSCtransplanted brain tissue, suggesting that IL-8 secretion by hUC-MSCs may improve the restoration of learning and memory function in HIBD rats. IL-8 is an important angiogenic factor [36] that enhances endothelial cell proliferation and survival and that regulates angiogenesis [37, 38]. Several independent reports have demonstrated that IL-8 stimulates VEGF expression via the MAPK signalling pathway $[19,39]$. In our study, we confirmed that hUC-MSC treatment significantly increased the expression levels of CD31 and VEGF in the HIBD brain and promoted angiogenesis in the hippocampus. Moreover, the level of p-JNK protein expression was clearly increased in the hUC-MSC-treated group. These data indicate that the IL-8 secreted by hUC-MSCs may regulates angiogenesis in the hippocampus of HIBD rats via the JNK signalling pathway.

To validate the effects of IL-8 from hUC-MSCs on hippocampal angiogenesis via the JNK pathway, we established a stable silL-8-hUC-MSC cell line. Following transplantation into the HIBD rats, we found that levels of both hIL-8 secretion and IL-8 protein expression were significantly decreased in the brain tissue. Moreover, levels of CD31 expression, VEGF release, p-JNK protein expression, and hippocampal angiogenesis were all significantly decreased by silL-8-hUC-MSC transplantation, thereby suggesting that the decrease in hUCMSC-secreted IL-8 can attenuate angiogenesis in the hippocampus of HIBD rats via the JNK pathway. Furthermore, the GFP-hUC-MSC transplantation group demonstrated greater benefits for treatment than the silL-8-hUC-MSC group, which verified the hypothesis that hUC-MSC transplantation improves the recovery of learning and memory functions via IL-8 secretion.

\section{Conclusion}

In summary, we demonstrated that hUC-MSCs exhibit the biological characteristics of stem cells and display neural directional differentiation potential. hUC-MSC transplantation improved the recovery of learning and memory functions via IL-8 secretion, which enhanced angiogenesis in the hippocampus of HIBD rats, but this treatment did not induce a differentiation pattern. These findings might provide the experimental foundation for the clinical application of hUC-MSCs to hypoxic-ischemic disorders.

\section{Abbreviations}

HIBD (Hypoxic-ischemic brain damage); MSCs (Mesenchymal stem cells); hUCMSCs (Human umbilical cord-derived mesenchymal stem cells); IL-8 (Interleukin-8); Dif (Differentiation status); Re-Dif (Redifferentiation status); fEPSPs (Field excitatory postsynaptic potentials); HFS (High frequency stimulation).

\section{Acknowledgement}

The reported work was supported by grants from the National Natural Science Foundation of China (Nos. 30830106 and 81271385) and the Stem Cell Therapy for Special Study of Children's Hospital of Chongqing Medical University (SCT-201203). 


\section{Cellular Physiology Cell Physiol Biochem 2015;35:2383-2401 \begin{tabular}{c|c}
\hline DOI: 10.1159/000374040 & (c) 2015 S. Karger AG, Basel
\end{tabular} and Biochemistry Published online: April 16, $2015 \quad$ www.karger.com/cpb \\ Zhou et al.: IL-8 from hUC-MSCs Improves HIBD Injury}

\section{Disclosure Statement}

The authors declare no conflict of interest.

\section{References}

1 Selway LD: State of the science: hypoxic ischemic encephalopathy and hypothermic intervention for neonates. Adv Neonatal Care 2010;10:60-66.

2 Bilen S, Pinarli F, Ak F, Fadillioglu E, Albayrak A, Boyuk G, Guler OG, Erden G, Ulus AT, Delibasi T: Treatment efficacy with bone marrow derived mesenchymal stem cells and minocycline in rats after cerebral ischemic injury. Stem Cell Rev 2013;9:219-225.

3 Wei L, Fraser JL, Lu ZY, Hu X, Yu SP: Transplantation of hypoxia preconditioned bone marrow mesenchymal stem cells enhances angiogenesis and neurogenesis after cerebral ischemia in rats. Neurobiol Dis 2012;46:635-645.

4 Huang B, Tabata Y, Gao JQ: Mesenchymal stem cells as therapeutic agents and potential targeted gene delivery vehicle for brain diseases. J Control Release 2012;162:464-473.

5 Bi Y, Gong M, He Y, Zhang X, Zhou X, Zhang Y, Nan G, Wei X, Liu Y, Chen J, Li T: AP2alpha transcriptional activity is essential for retinoid-induced neuronal differentiation of mesenchymal stem cells. Int J Biochem Cell Biol 2014;46:148-160.

6 Gong M, Bi Y, Jiang W, Zhang Y, Chen L, Hou N, Liu Y, Wei X, Chen J, Li T: Immortalized mesenchymal stem cells: an alternative to primary mesenchymal stem cells in neuronal differentiation and neuroregeneration associated studies. J Biomed Sci 2011;18:87.

$7 \quad$ Nagamura-Inoue T, He H: Umbilical cord-derived mesenchymal stem cells: Their advantages and potential clinical utility. World J Stem Cells 2014;6:195-202.

8 Fink KD, Rossignol J, Crane AT, Davis KK, Bombard MC, Bavar AM, Clerc S, Lowrance SA, Song C, Lescaudron L, Dunbar GL: Transplantation of umbilical cord-derived mesenchymal stem cells into the striata of R6/2 mice: behavioral and neuropathological analysis. Stem Cell Res Ther 2013;4:130.

9 Smith HK, Gavins FN: The potential of stem cell therapy for stroke: is PISCES the sign? FASEB J 2012;26:2239-2252.

10 Lee ST, Chu K, Jung KH, Kim SJ, Kim DH, Kang KM, Hong NH, Kim JH, Ban JJ, Park HK, Kim SU, Park CG, Lee SK, Kim M, Roh JK: Anti-inflammatory mechanism of intravascular neural stem cell transplantation in haemorrhagic stroke. Brain 2008;131:616-629.

11 Ergul A, Alhusban A, Fagan SC: Angiogenesis: a harmonized target for recovery after stroke. Stroke 2012;43:2270-2274.

12 Mine Y, Tatarishvili J, Oki K, Monni E, Kokaia Z, Lindvall O: Grafted human neural stem cells enhance several steps of endogenous neurogenesis and improve behavioral recovery after middle cerebral artery occlusion in rats. Neurobiol Dis 2013;52:191-203.

13 Chen J, Li Y, Wang L, Lu M, Zhang X, Chopp M: Therapeutic benefit of intracerebral transplantation of bone marrow stromal cells after cerebral ischemia in rats. J Neurol Sci 2001;189:49-57.

14 Chen J, Li Y, Wang L, Zhang Z, Lu D, Lu M, Chopp M: Therapeutic benefit of intravenous administration of bone marrow stromal cells after cerebral ischemia in rats. Stroke 2001;32:1005-1011.

15 Koh SH, Kim KS, Choi MR, Jung KH, Park KS, Chai YG, Roh W, Hwang SJ, Ko HJ, Huh YM, Kim HT, Kim SH: Implantation of human umbilical cord-derived mesenchymal stem cells as a neuroprotective therapy for ischemic stroke in rats. Brain Res 2008;1229:233-248.

16 Ma K, Fox L, Shi G, Shen J, Liu Q, Pappas JD, Cheng J, Qu T: Generation of neural stem cell-like cells from bone marrow-derived human mesenchymal stem cells. Neurol Res 2011;33:1083-1093.

17 Matsuse D, Kitada M, Kohama M, Nishikawa K, Makinoshima H, Wakao S, Fujiyoshi Y, Heike T, Nakahata T, Akutsu H, Umezawa A, Harigae H,Kira J, Dezawa M: Human umbilical cord-derived mesenchymal stromal cells differentiate into functional Schwann cells that sustain peripheral nerve regeneration. J Neuropathol Exp Neurol 2010;69:973-985.

18 Zhang X, Zhang Q, Li W, Nie D, Chen W, Xu C, Yi X, Shi J, Tian M, Qin J, Jin G, Tu W: Therapeutic effect of human umbilical cord mesenchymal stem cells on neonatal rat hypoxic-ischemic encephalopathy. J Neurosci Res 2014;92:35-45. 


\section{Cellular Physiology Cell Physiol Biochem 2015;35:2383-2401 \begin{tabular}{ll|l} 
and Biochemistry & $\begin{array}{l}\text { DOI: 10.1159/000374040 } \\
\text { Published online: April 16, } 2015\end{array}$ & $\begin{array}{l}\text { ○ 2015 S. Karger AG, Basel } \\
\text { www.karger.com/cpb }\end{array}$ \\
\hline
\end{tabular} Zhou et al.: IL-8 from hUC-MSCs Improves HIBD Injury}

19 Kwon YW, Heo SC, Jeong GO, Yoon JW, Mo WM, Lee MJ, Jang IH, Kwon SM, Lee JS, Kim JH: Tumor necrosis factor-alpha-activated mesenchymal stem cells promote endothelial progenitor cell homing and angiogenesis. Biochim Biophys Acta 2013;1832:2136-2144.

20 Liu Y, Jiang X, Zhang X, Chen R, Sun T, Fok KL, Dong J, Tsang LL, Yi S, Ruan Y, Guo J, Yu MK, Tian Y, Chung YW, Yang M, Xu W, Chung CM, Li T, Chan HC: Dedifferentiation-reprogrammed mesenchymal stem cells with improved therapeutic potential. Stem Cells 2011;29:2077-2089.

21 Rice JE, 3rd, Vannucci RC, Brierley JB: The influence of immaturity on hypoxic-ischemic brain damage in the rat. Ann Neurol 1981;9:131-141.

22 Dominici M, Le Blanc K, Mueller I, Slaper-Cortenbach I, Marini F, Krause D, Deans R, Keating A, Prockop Dj, Horwitz E: Minimal criteria for defining multipotent mesenchymal stromal cells. The International Society for Cellular Therapy position statement. Cytotherapy 2006;8:315-317.

23 Wei L, Zhang J, Xiao XB, Mai HX, Zheng K, Sun WL, Wang L, Liang F, Yang ZL, Liu Y, Wang YQ Li ZF, Wang JN, Zhang WJ, You H: Multiple injections of human umbilical cord-derived mesenchymal stromal cells through the tail vein improve microcirculation and the microenvironment in a rat model of radiation myelopathy. J Transl Med 2014;12:246.

24 Chen G, Yue A, Ruan Z, Yin Y, Wang R, Ren Y, Zhu L: Human umbilical cord-derived mesenchymal stem cells do not undergo malignant transformation during long-term culturing in serum-free medium. PloS One 2014;9:e98565.

25 Lu LL, Liu YJ, Yang SG, Zhao QJ, Wang X, Gong W, Han ZB, Xu ZS, Lu YX, Liu D, Chen ZZ, Han ZC: Isolation and characterization of human umbilical cord mesenchymal stem cells with hematopoiesis-supportive function and other potentials. Haematologica 2006;91:1017-1026.

26 Jiang J, Lv Z, Gu Y, Li J, Xu L, Xu W, Lu J, Xu J: Adult rat mesenchymal stem cells differentiate into neuronallike phenotype and express a variety of neuro-regulatory molecules in vitro. Neurosci Res 2010;66:46-52.

27 Schultz SS, Lucas PA: Human stem cells isolated from adult skeletal muscle differentiate into neural phenotypes. J Neurosci Methods 2006;152:144-155.

28 Gong M, Bi Y, Jiang W, Zhang Y, Chen L, Hou N, Chen J, Li T: Retinoic acid receptor beta mediates all-trans retinoic acid facilitation of mesenchymal stem cells neuronal differentiation. Int J Biochem Cell Biol 2013;45:866-875.

29 Hedtjarn M, Mallard C, Hagberg H: Inflammatory gene profiling in the developing mouse brain after hypoxia-ischemia. J Cereb Blood Flow Metab 2004;24:1333-1351.

30 Donega V, van Velthoven CT, Nijboer CH, van Bel F, Kas MJ, Kavelaars A, Heijnen CJ: Intranasal mesenchymal stem cell treatment for neonatal brain damage: long-term cognitive and sensorimotor improvement. PloS One 2013;8:e51253.

31 van Velthoven CT, Kavelaars A, van Bel F, Heijnen CJ: Mesenchymal stem cell transplantation changes the gene expression profile of the neonatal ischemic brain. Brain Behav Immun 2011;25:1342-1348.

32 Watanabe Y, Sasaki R, Matsumine H, Yamato M, Okano T: Undifferentiated and differentiated adiposederived stem cells improve nerve regeneration in a rat model of facial nerve defect. J Tissue Eng Regen Med 2014. Jun 1.

33 Orbay H, Uysal AC, Hyakusoku H, Mizuno H: Differentiated and undifferentiated adipose-derived stem cells improve function in rats with peripheral nerve gaps. J Plast Reconstr Aesthet Surg 2012;65:657-664.

34 Drago D, Cossetti C, Iraci N, Gaude E, Musco G, Bachi A, Pluchino S: The stem cell secretome and its role in brain repair. Biochimie 2013;95:2271-2285.

35 Joyce N, Annett G, Wirthlin L, Olson S, Bauer G, Nolta JA: Mesenchymal stem cells for the treatment of neurodegenerative disease. Regen Med 2010;5:933-946.

36 Koch AE, Polverini PJ, Kunkel SL, Harlow LA, DiPietro LA, Elner VM, Elner SG, Strieter RM: Interleukin-8 as a macrophage-derived mediator of angiogenesis. Science 1992;258:1798-1801.

37 Li A, Varney ML, Valasek J, Godfrey M, Dave BJ, Singh RK: Autocrine role of interleukin-8 in induction of endothelial cell proliferation, survival, migration and MMP-2 production and angiogenesis. Angiogenesis 2005;8:63-71.

38 Li A, Dubey S, Varney ML, Dave BJ, Singh RK: IL-8 directly enhanced endothelial cell survival, proliferation, and matrix metalloproteinases production and regulated angiogenesis. J Immunol 2003;170:3369-3376.

39 Hou Y, Ryu CH, Jun JA, Kim SM, Jeong CH, Jeun SS: IL-8 enhances the angiogenic potential of human bone marrow mesenchymal stem cells by increasing vascular endothelial growth factor. Cell Biol Int 2014;38:1050-1059. 